\title{
Concussion knowledge assessment and educational intervention in parents of youth football players
}

\author{
Colin Eckert, Gordon L. Gillespie, Kimberly Johnson \\ College of Nursing, University of Cincinnati, United States
}

Received: September 16, 2020

Accepted: November 8, 2020

Online Published: November 13, 2020

DOI: $10.5430 /$ jnep.v11n3p24

URL: https://doi.org/10.5430/jnep.v11n3p24

\begin{abstract}
Sports related concussions have become a major topic within the pediatric community. This project's aim was to address gaps in care by providing parents of youth football players with a concussion educational tool. Pre and post season assessments were performed to analyze both baseline parental concussion knowledge and any possible application of gained knowledge. The project's purpose was twofold: first, to test the hypothesis that there would be a significant improvement in knowledge score post intervention, and second, to introduce concussion education to parents where previous education did not exist.
\end{abstract}

Key Words: Sports related concussions, Pediatric community, Parents, Education

\section{BACKGROUND}

Sports related concussions (SRC) have become a major topic within the pediatric community. Concussion misconceptions, symptom ambiguity, and parental knowledge deficits may contribute to potential adverse outcomes, ranging from intracranial injury to problems with attention. ${ }^{[1]}$ In 2014 alone, there were more than 500,000 emergency department visits for 8-19 year old patients due to concussion. ${ }^{[2]}$ Education can positively impact parental concussion knowledge, particularly regarding concussion recognition and management. ${ }^{[3]}$ However, non-standardization of parental concussion education can contribute to inadequate knowledge. For example, the Concussion Law in Ohio (United States) mandates universal statewide education for all players, coaches, and parents. ${ }^{[4]}$ However, in New Jersey (United States), standardization of required parental education at levels below high school does not exist. ${ }^{[5]}$ This inconsistency may lead to deficient parental education, which could be particularly disastrous in culturally and socioeconomically diverse communities where addressing gaps in care and education is vital. ${ }^{[6]}$
Providing parents of youth football players with concussion education may prevent negative clinical outcomes, reduce neuroimaging referrals, and increase concussion reporting. ${ }^{[1]}$

While examining a local youth football (K-8) program's concussion education plan, it was discovered that there was no mandated parental concussion education. This project's aim was to address gaps in care by providing parents with a concussion educational tool. Pre and post season assessments analyzed both parental concussion knowledge and possible application of gained knowledge. The purpose of this project was twofold: first, to test the hypothesis that there would be a significant improvement in knowledge score after completing the intervention training, and second, to introduce concussion education to parents where previous education did not exist.

\section{MeThODS}

\subsection{Study design}

This quality improvement project served as a pilot study to assess concussion knowledge of parents of players in a lo-

*Correspondence: Colin Eckert; Email: ceck48@ hotmail.com; Address: College of Nursing, University of Cincinnati, P.O. Box 210038 Cincinnati, OH 452210 United States. 
cal youth (kindergarten-8th grade) football program from August 2019 to November 2019 in Northern New Jersey. This population was chosen due to the lack of mandated parental concussion education for this region. In addition, the first author's previous experience as a football coach at both the high school and youth levels left a lasting impression regarding the need for parental concussion education. A preseason questionnaire was administered to parents to assess baseline knowledge; upon completion, parents received a concussion educational packet. After the season, parents repeated the questionnaire to assess for education efficacy and applicability of knowledge gained.

\subsection{Intervention}

The educational tool was a 2-page printout published by the Centers for Disease Control and Prevention. ${ }^{[7]}$ The printout was part of the CDC's "HEADS UP" program, which uses various educational formats with the intent to protect children and teens from the effects of concussions. ${ }^{[3]}$ The handout answered such questions as, "What is a concussion?", "What are the signs and symptoms of a concussion?", "What should I do if my child or teen has a concussion?", and "How can I help my child return to school safely after a concussion?", as well as a description of concussion signs and symptoms of a concussion. The handout was chosen based on its "parent friendly" format, as well as its wide spread use. ${ }^{[8]}$

\subsection{Parental questionnaire}

The questionnaire assessed different aspects of pediatric concussions, including basic definition, signs and symptoms, parental management, clinical presentation, and recovery. The preseason questionnaire had descriptive questions about the child's age and concussion diagnosis history; the postseason questionnaire included the same questions, as well as questions about concussion diagnosis during the season and the value of the experience. The questions were directly related to the content provided in the CDC's "HEADS UP" program printout. ${ }^{[7]}$

\subsection{Participant recruitment and data collection}

The president of a local township kindergarten through 8th grade football program facilitated access to parents of football players. Parent contact was initiated by the program president through email, as well as asking the head coach of each program level to request volunteers.

Although all program levels were contacted for participation, only parents of $9,10,11,12$, and 13-year-old football players attended the preseason meeting and completed the questionnaires, while only parents of 12 and 13-year-old football players completed the postseason questionnaire. Parents were given an unlimited amount of time to complete the

Published by Sciedu Press questionnaire, and instructed not to include any identifiable information.

\subsection{Procedures}

Questionnaires and education were distributed at a preseason meeting in August 2019. To promote postseason participation, parents were sent the questionnaire through Survey Monkey in November 2019. The preseason parental assessment and education session lasted for approximately $30 \mathrm{~min}$ utes. To optimize adult learning environment variability for the adult learner, a question and answer period took place after the assessment, ${ }^{[3]}$ during which time concussion topics were elaborated upon.

\subsection{Statistical analysis}

The preseason and postseason questionnaires were scored: correct answers $=1$ and incorrect answers $=0$. Answers were summed to yield a questionnaire score. Responses to individual items and overall score were analyzed using descriptive statistics. Due to the inability to match preseason and postseason questionnaires (i.e., data collected anonymously) and small sample size, a Mann-Whitney U test was calculated to determine if a significant improvement in post-concussion knowledge occurred. Alpha was set at 0.05.

\section{FINDINGS}

Twenty-six participants completed the preseason survey and seven participants completed the postseason survey. Preseason participants were parents of football players ranging in age from 9 to 13 years old (see Table 1) and the postseason participants had football players ranging from 12 to 13 year olds. Due to lack of respondents for parents of players less than 12 years old, descriptive results and group comparisons were focused on responses from players aged 12 and 13 years old.

Parents of 12 and 13 year old players constituted $52 \%$ of the preseason group and $100 \%$ of the postseason group. There was moderate improvement in certain questions when comparing preseason to postseason responses (see Table 2). For example, improvements between preseason and postseason groups with correct responses were found for questions discussing concussion resolution and differentiating between concussions and typical cold symptoms. Questions regarding concussion dissipation and the presentation difference between a concussion and a typical flu showed improvement between the groups $(42.3 \%$ vs. $85.7 \%$ and $65.4 \%$ vs. $85.7 \%$, respectively). However, certain questions produced low rates of correct responses for both groups. A question about possible actions to ensure recovery following a concussion produced low scores for both groups; this has the 
potential to delay return to play. One item had low scores (14.3\% and $0 \%)$ for both groups concerning recognizing danger signs around a concussion. Finally, 7 (27\%) preseason parents reported their son had previously been diagnosed with a concussion. Parents of three players (42\%) reported that their son had been diagnosed with a concussion during the season. Seven $(100 \%)$ of postseason parents reported the preseason questionnaire was helpful during the course of the season.

Table 1. Descriptive statistics for study sample and findings

\begin{tabular}{lll}
\hline Characteristic & Preseason (n) & Postseason (n) \\
\hline Age & 4 & 0 \\
9 & 3 & 0 \\
10 & 5 & 0 \\
11 & 12 & 6 \\
12 & 1 & 1 \\
13 & $27 \%$ & $43 \%$ \\
Child with history of concussion & Not applicable & $43 \%$ \\
Experienced concussion during current season & $60 \%$ & $70 \%$ \\
Test score (median, full sample) & $60 \%$ & $70 \%$ \\
Test score (median, age 12 and 13 only) & & \\
\hline
\end{tabular}

Table 2. Parental questionnaire with response findings for football players age 12 and 13 years old

\begin{tabular}{lll} 
& \multicolumn{2}{l}{ Percentage with correct responses } \\
\cline { 2 - 3 } & Preseason & Postseason \\
\hline 1) What is a concussion? & $71.4 \%$ & $71.4 \%$ \\
2) A concussion will not result in loss of consciousness (“blacking out”). & $64.2 \%$ & $57.1 \%$ \\
3) A simple concussion injury may resolve (without complication) within: & $57.1 \%$ & $85.7 \%$ \\
4) A concussion may differ from a typical cold or flu by: & $78.6 \%$ & $85.7 \%$ \\
5) Select all that are signs of a concussion: & $42.9 \%$ & $42.9 \%$ \\
6) Select 3 physical symptoms which may be reported by a concussed child: & $92.9 \%$ & $100 \%$ \\
7) After a game, your child has vomited twice and reports feeling “off balance”. As a parent, & $100 \%$ & $100 \%$ \\
you suspect a concussion. You should: & & $100 \%$ \\
8) What test may my practitioner order if I bring my child to a clinic or hospital for a & $100 \%$ & $14.3 \%$ \\
suspicion of a concussion? & $14.3 \%$ & $0 \%$ \\
9) Select all danger signs which may indicate injury due to a concussion: & & \\
10) As a parent, what can you do to help ensure recovery following a concussion diagnosis? & $14.3 \%$ & \\
\hline
\end{tabular}

\subsection{Statistical analysis results}

The preseason group's median percentage of correct answers was $60 \%$, and the postseason group's median percentage of correct answers was $70 \%$. A nonparametric test was used to test the hypothesis, "There will be a significant improvement in test score after completing the intervention training". A Mann Whitney U statistic was used to test the hypothesis. Although the median increased from preseason to postseason, the change was not statistically significant $(\mathrm{U}=0.382, p=$ .537).

\section{Discussion}

The overall aim of this project was to evaluate the change in knowledge attainment following an educational intervention on concussion. The change between preseason and postseason test scores was not statistically significant $(p=.279)$; this lack of statistical significance could be due to the smaller sample size of postseason respondents. However, results from questions surrounding danger sign recognition and concussion recovery tactics were poor in both groups. This is similar to assessments performed by Rieger et al., ${ }^{[9]}$ who showed great variability in parental input concerning aspects of recovery. These may be important areas on which to focus educational efforts, as they may affect management initiation, as well as return to play. Anecdotally, all preseason and postseason respondents commented that the assessment and the educational tool were useful, indicating they have the potential to set a precedent of yearly parental education in 
this specific program.

Parents also were asked to choose all danger signs indicating a concussion, and were provided options such as vomiting, loss of consciousness, and unintelligible speaking. Low scores with this specific question are troubling, as not recognizing signs (particularly signs of severe neurologic injury) may delay much needed treatment. Rice and Curtis discussed presenting adult learners with certain "need to know" information, as opposed to providing general concussion education material. $^{[3]}$ Ensuring parents understand acute (and potentially severe) danger signs may fall under "need to know" material, and can help form education in the future.

Quality improvement related to this project was multifaceted; it consisted of assessing baseline knowledge, introducing a tool to potentially improve outcomes, and assessing the efficacy of the educational tool. When examining the results from both sets of assessments, it becomes clear how developing future parental educational opportunities can be tailored to content that is most vital. These assumptions reflect conclusions in studies by Lin et al. and Rice and Curtis, ${ }^{[3,6]}$ which highlight the need for constant assessment and tool refinement in order to fill knowledge gaps and ultimately affect outcomes. Also, as Rice and Curtis noted, the type of assessment tool needs to be customized to adult learners. ${ }^{[3]}$ A multiple-choice questionnaire and two-page educational handout may not be an optimal mode of assessment and instruction for adult learners. Parental history of concussion, previous sports experience, parental education level, and socioeconomic demographics may also prove helpful, as these can affect baseline knowledge. ${ }^{[6]}$

Concurrently, the questions on the assessment itself and the content of the educational tool should be modified for future improvement. For example, open-ended questions may be more beneficial, as parents can elaborate on their answer. Also, a paper educational tool might not be as effective of a modality for education in this specific population versus video, etc. In a 2019 study comparing concussion education via handout or video, Rice and Curtis found knowledge improved regardless of intervention. ${ }^{[3]}$ Future parental education efforts may warrant experimenting with different modes of instruction to potentially provide a broader benefit.

This pilot study can help drive future efforts, such as focusing on parental retention, and educating the parents and players simultaneously. Limitations of this project include the small sample size and the lack of retention for the postseason assessment. Although the limited number of postseason respondents did state the preseason assessment and tool were beneficial, the small sample size and lack of statistical significance surrounding score makes it difficult to determine the overall efficacy of the tool. It is also possible a different parent completed the preseason vs. postseason surveys.

\section{Conclusion}

This study introduced concussion education to a parental population where education did not previously exist. A preseason assessment provided insight into parents' baseline knowledge level. Some responses produced troubling results, which should be areas on which to focus in future education. To promote education and safety for youth football players, nurses can advocate for yearly preseason parental concussion education. In addition, alternate modes of education can be trialed in order to increase knowledge attainment.

\section{Conflicts of InTEREST Disclosure}

The authors declare that there is no conflict of interest.

\section{REFERENCES}

[1] Halstead ME, Walter KD, Moffatt K. Sport-related concussion in children and adolescents. Pediatrics. 2018; 142(6). PMid:30420472 https://doi.org/10.1542/peds. 2018-3074

[2] Broglio SP, Cantu RC, Gioia GA, et al. National Athletic Trainers' Association position statement: management of sport concussion. Journal of Athletic Training. 2014; 49(2): 245-265. PMid:24601910 https://doi.org/10.4085/1062-6050-49.1.07

[3] Rice T, Curtis R. Parental knowledge of concussion: Evaluation of the CDC's "Heads up to parents" educational initiative. Journal of Safety Research. 2019; 69: 85-93. PMid:31235239 https: //doi.org/10.1016/j.jsr.2019.02.007

[4] Ohio Department of Health. Return-to-play-What parents need to know-Youth sports organizations. 2019. Available from: https: //odh.ohio.gov/wps/portal/gov/odh/know-our-program s/child-injury-prevention/media/return-to-play-wha t-parents-need-to-know-youth-sports-organizations

[5] New Jersey State Interscholastic Athletic Association. Model policy and guidelines for prevention and treatment of sports- related concussions and head injuries. 2011. Available from: https://www.njsiaa.org/sites/default/files/documen t/11ConcussionModelPolicyDOE.pdf

[6] Lin AC, Salzman GA, Bachman SL, et al. Assessment of parental knowledge and attitudes toward pediatric sports-related concussions. Sports Health: A Multidisciplinary Approach. 2015; 7(2). PMid:25984257 https://doi.org/10.1177/19417381155715 70

[7] Centers for Disease Control and Prevention. Heads up schools: A fact sheet for parents. Available from: https://www.cdc.gov/he adsup/index.html

[8] Macdonald I, Hauber R. Educating parents on sports-related concussions. Journal of Neuroscience Nursing. 2016; 48(6). PMid:27824798 https://doi.org/10.1097/JNN.0000000000000212

[9] Rieger B, Lewandowski L, Potts H, et al. Parent knowledge and perceptions of concussion related to youth football. Cureus. 2018; 10(3).

Published by Sciedu Press 